\title{
Early detection of lung cancer: role of biomarkers
}

\author{
C. Brambilla*,\#, F. Fievet*,\#, M. Jeanmart*,\#, F. de Fraipont", ${ }^{\#, \text { S. Lantuejoul }}{ }^{\#,+}$, V. Frappat*,\#, \\ G. Ferretti ${ }^{\#, \S}$, P.Y. Brichon ${ }^{\#, f}$, D. Moro-Sibilot*,\#
}

Early detection of lung cancer: role of biomarkers. C. Brambilla, F. Fievet, M. Jeanmart, F. de Fraipont, S. Lantuejoul, V. Frappat, G. Ferretti, P. Y. Brichon, D. Moro-Sibilot. (C) ERS Journals Ltd 2003.

ABSTRACT: Early detection of lung cancer requires none or few invasive techniques. Distal lung cancer $(40 \%$ of the cases in most European countries) can be sensitively detected by spiral computed tomography. Theoretically, in $60 \%$ of cases, the proximal lesions (main to segmental bronchi, accessible by bronchoscopy) should be able to be detected by sputum cytology. Unfortunately, this very specific technique has a low sensitivity and is time consuming. Fluorescent bronchoscopy increases the detection rate of early or micro-invasive lesions and may be proposed in highly selected populations, but not as a screening test. Biomarkers in blood and sputum have not yet been clinically validated. However, the amount of data generated from studies first on resected tumours, then on early bronchial lesions and more recently on blood and sputum offer a wide field for investigation.

Lung carcinogenesis is a multistep process characterised by the accumulation of successive molecular genetic and epigenetic abnormalities, resulting in selection of clonal cells with uncontrolled growth capacities throughout the whole respiratory tract (field cancerisation). Molecular lesions far precede morphological transformation of preneoplastic bronchial lesions (dysplasia) or alveolar lesions (atypical alveolar hyperplasia). Genetic and epigenetic abnormalities in the genes involved in cell cycle, senescence, apoptosis, repair, differentiation and cell migration control may be detected on bronchial biopsies, on respiratory cells from the sputum and even in the circulating deoxyribonucleic acid (DNA). The key genes involved include those in the P53retinoblastoma $(\mathrm{Rb})$ pathways.

The balance between cyclin-dependent kinases and their inhibitors regulates the level of Rb phosphorylation and its function at G1-S transition; P53 plays at least two functions (cell cycle and apoptosis control). The balance of bax-bcl2 is important in the control of apoptosis as well as loss of fragile histidine triad expression. $\mathrm{O}(6)$ methylguanine-DNA methyltransferase seems to be important in DNA repair control, the RARB receptor in differentiation, and cadherin $H$ and $E$ and different metalloproteases genes in cell migration.

The demonstration of hyperexpression or silencing of these genes needs different validated techniques: immunohistochemistry on biopsies or cytological preparations, molecular biology techniques for mutations, loss of heterozygosity and aberrant methylation abnormalities. Automation and miniaturisation of these techniques will allow early detection and may be widely applied once clinically validated.

Eur Respir J 2003; 21: Suppl. 39, 36s-44s.
*Département de Médecine Aiguë Spécialisée, "Département de Biologie Intégrée, ${ }^{+}$Service de Pathologie Cellulaire, Service de Radiologie Centrale, and ${ }^{f}$ Service de Chirurgie Thoracique, Centre Hospitalier Universitaire, Grenoble, and "EMI 99-24 Equipe Mixte INSERM Université: "Molecular Basis of Lung Cancer progression", Institut Albert Bonniot Rond Point de la Chantourne, La Tronche, France.

Correspondence: C. Brambilla,

Département de Médecine Aiguë

Spécialisée

$\mathrm{CHU}$

BP 217 X 38043

Grenoble cedex 9

France

Fax: 33476765364

E-mail: cbrambilla@chu-grenoble.fr

Keywords: Biomarkers

early detection

fluorescent bronchoscopy

lung cancer

methylation

preneoplasia

Received: July 102002

Accepted after revision: August 222002

This group was supported by grants from DRC Grenoble, Equipe labellisée "La Ligue".
Lung cancer is the leading cause of cancer-related death, not only in males all around the world but also in females [1-3]. Despite the advances made in diagnosis and treatment in the last few decades, the prognosis of lung cancer is still very poor, with a 5-yr overall survival generally $<10 \%$ in many countries. Lung cancer is detected by symptoms at a time when the local and moreover the metastasis extension hamper any hope of cure. Besides tobacco cessation and tobacco prevention, early detection of lung cancer is clearly the only way to improve the overall survival in the lung cancer epidemic. Detection of lung cancer-related antigens in the blood, such as carcino-embryonic antigen, failed to be of use in early detection. However, the amount of data generated from studies of oncogene activation and the range of molecular and genetic abnormalities on resected tumours [4-7] has opened a wide field of investigation and most of the groups working on lung cancer are currently trying to validate accurate biomarkers for the early detection of lung cancer.

\section{Multistep carcinogenesis and field cancerisation}

Lung carcinogenesis is a multistep and multicentric process, characterised by the stepwise accumulation of genetic and molecular abnormalities after carcinogen exposure, resulting in the selection of clonal cells with uncontrolled growth capacities [8-11]. Molecular lesions 
occur in normal looking epithelium in the absence of dysplasia. These have been shown to precede the morphological step of preneoplastic bronchial lesions, which are described as metaplasia, mild dysplasia, moderate dysplasia, severe dysplasia and carcinoma in situ (CIS) [12, 13]. As metaplasia in smokers displays genetic abnormalities, it can now be considered as a preneoplastic lesion. These lesions are multiple, reflecting the fact that the carcinogenic process may randomly affect any site in the bronchial tree and concomitant lesions can be of different ages and might progress at different rates towards invasion [14-17]. This typically represents the field cancerisation process defined previously. There is no definite prediction of delay of progression to invasion that can be deduced from the morphological grade, since even CIS may progress or regress. The current hypothesis is that molecular characteristics of any individual lesion, with regard to deregulation of cell cycle or apoptosis, might reflect its potential for progression [18-20]. However, most highgrade lesions are now treated locally, which means that their natural history cannot be clearly understood. Alternatively, the cumulative rate of molecular abnormalities at any random lesion, regardless of its morphological grade, might reflect the severity of the cancerisation field and be predictive of the susceptibility of an individual patient to develop a cancer in the bronchial tree (fig. 1). In the lung parenchyma, atypical alveolar dysplasia, considered as a preneoplastic lesion preceding bronchiolo-alveolar carcinoma, also exhibits genetic abnormality accumulation [21, 22].

The accumulation of genetic and molecular abnormalities leads to an uncontrolled growth of clonal cells and an increased ability of these cells to migrate, which characterises cancer progression, i.e. tumour growth and metastasis. Uncontrolled growth and migration of a cell can be summarised as the dysbalance between the activation of oncogenes, which drive the cell to multiply and migrate, and the inactivation of tumour suppressor genes (TSG) [18] (fig. 2). The activation of oncogenes may be due to genetic modification: mutation, amplification, chromosomal rearrangement or epigenetic modification such as hyperexpression. TSG inactivation may be due to genetic modification (mutation,

\section{Normal Hyperplasia Metaplasia Dysplasia ISC Carcinoma}

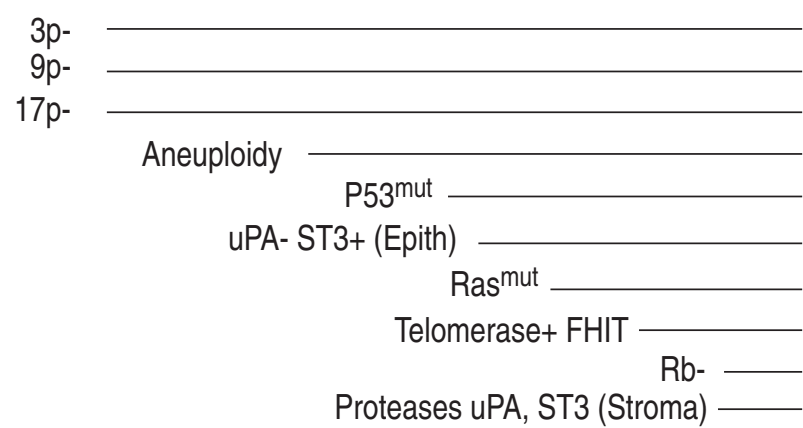

Fig. 1.-Chronology of genetic and molecular lesions. ISC: in situ carcinoma; uPA: urokinase type plasminogen activator; ST3: stromelysin 3; FHIT: fragile histidine triad; Rb: retinoblastoma; mut: mutation; +: activation; -: inactivation.

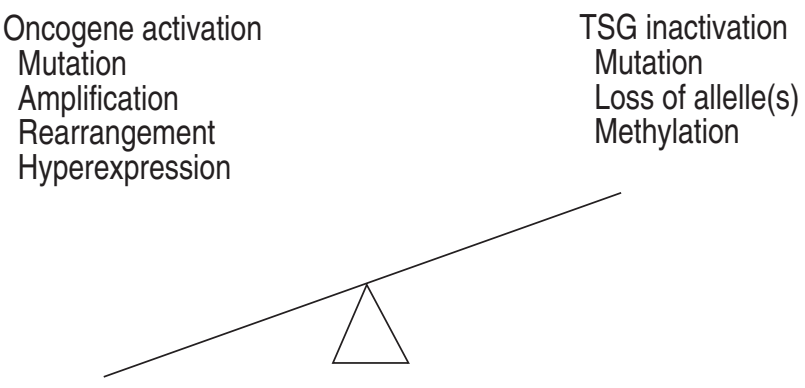

Fig. 2.- The involvement of oncogenes and tumour suppressor genes (TSG) in tumour growth and metastasis.

loss of chromosomal material (one or two alleles) or an epigenetic phenomenon such as methylation). Genetic modifications seem difficult to correct without a very well-targeted gene transfer. Epigenetic modifications seem more easily accessible to pharmacological therapy (demethylating agents). Therapeutic efforts are also directed at the result of a genetic modification (e.g. farnelysating agents to block the pathway of a mutated ras gene). Oncogenes are generally considered as dominant genes and TSG as recessive genes needing modification on both chromosomes to inactivate the gene. Whatever the mechanisms, the loss of expression or, on the contrary, the hyperexpression of a protein are the best methods to show the inactivation or the activation of a gene. All the methods of detection of malignant cells at the deoxyribonucleic acid (DNA), ribonucleic acid (RNA) or protein level may be applied on different samples obtained from the patient (blood, sputum, biopsies). However, to be used as a biomarker they need to fulfil different requirements.

\section{Mechanisms of genetic and molecular abnormalities: gene silencing and overexpression}

During cellular division, the loss of DNA or chromosomal rearrangement increases with the rate of synthesis and division. It was shown several years ago, using cytogenetic techniques, that deletion of the short arm of chromosome $3(3 \mathrm{p})$ is very frequent in lung cancer. Like other chromosomal deletions, it corresponds to a site where one or several TSG are present and therefore inactivated. For a TSG previously identified, it is easy to check the deletion on the corresponding chromosomal site. In contrast, repetitive deletions at an unexpected chromosomal site indicate the need to seek a new putative TSG at this location by identifying mutations or methylations on the remaining allele. Due to the high density and the large size of the deletion on $3 p$ the number of TSG(s) suspected at that location is high. Fragile histidine triad (FHIT) seems a good proposition at 3p14.2 [23].

Loss of chromosomal material not visible with classical cytogenetic techniques can also be shown. First, several probes can be used, which specifically complement a part of a pair of chromosomes in which a known or a putative TSG is located. After amplification of the DNA and electrophoretic migration, 
the two bands corresponding to the maternal and paternal chromosomes are separated owing to the slight polymorphism of those two chromosomes. The heterozygosity of the gene visible in normal tissue, such as in lymphocytes from the blood, is then compared with its loss of allele on tumour cells where only one band is visible, demonstrating the loss of one allele or loss of heterozygosity (LOH). This loss is an early event frequently detected on different chromosomes (3p14, 9p21, 17p13, 13q14, 5q21, 1q, 2q, 8q) and they may be detected in histologically normal or metaplastic epithelium in smokers or exsmokers [19, 20, 23].

LOH can now be studied with miniaturised and automated techniques on microarray [24]. This allows a wider study of chromosome loci and a decrease in artefacts, due to the preparation of the sample using small sequences such as the single nucleotide polymorphism. The limit of these techniques is the need for a high ratio of neoplastic cells to avoid contamination by surrounding normal cells and the need for microdissection on samples such as bronchial biopsies. In sputum, separation of epithelial cells is probably necessary to avoid contamination by inflammatory cells. The number and frequency of $\mathrm{LOH}$ at specific gene loci have been clearly shown to increase with the severity of the bronchial preinvasive lesions. Homozygous deletion, that is the loss of the two alleles of a single gene, can be shown using the fluorescence in situ hybridisation technique with the simultaneous fixation of a gene-specific probe and a centrometric probe of the same chromosome [25]. It indicates the complete inactivation of the gene, but at the present time this technique is difficult to apply on a large scale as it is time consuming.

Aberrant gene methylation is a preferential method for gene silencing. One way to control the expression of a gene is through methylation of the cytosine phosphate guanosine rich regions ( $\mathrm{CpG}$ islands) of the chromosome (fig. 3). Most of the chromosomes in a vertebrate are inactivated and the only unmethylated areas are those where the concentration of the $\mathrm{CpG}$ island is high and this corresponds to the promoters of the gene. An aberrant methylation in one of these areas induces a silencing of the gene. Tumours generally exhibit a global hypermethylation and a regional promoter hypermethylation that is associated with silencing of gene expression. The discovery of numerous hypermethylated promoter regions in TSGs along with a better understanding of gene silencing

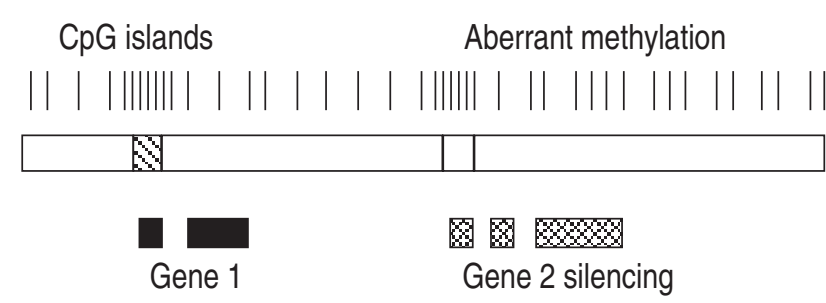

Fig. 3. - The aberrant methylation of cytosine phosphate guanosine rich regions (CpG sites) of the promoter induce a silencing of the gene expression. $\square$ : methylated $\mathrm{CpG}$ sites; $\mathbb{\mathbb { N }}$ : nonmethylated $\mathrm{CpG}$ sites. mechanisms indicates that DNA methylation is an alternative mechanism of inactivation of TSGs. In lung cancer [26-32], DNA methylation contributes to inactivation of numerous TSGs such as P16, P15, glutathione transferase 1, O(6)-methylguanine-DNA methyltransferase $\left(\mathrm{O}^{6}-\mathrm{MGMT}\right)$, tissue inhibitor of metalloprotease (TIMP)-3 and death associated protein (DAP)-kinase. Aberrant methylation can be shown using particular amplification techniques (methylationspecific polymerase chain reaction (PCR)). This technique seems promising not only on microdissected tissue but also on sputum and circulating DNA conserved in simple fixative. The increasing number of genes to study will probably require the use of methylation microarrays.

The use of microarrays in the search for mutations will be also necessary since classical sequencing or approaching techniques are difficult to apply on a large scale and the number of different possible mutations may be high (P53 for instance) [33]. Gene-specific or even lung cancer-specific microarrays are presently at different stages of realisation.

When antibodies directed against an oncogene or a TSG are available, the simplest way to evaluate the hyperexpression or the loss of expression of a gene is by immunohistochemistry [34, 35]. Differences in kinetics between wild or mutant proteins can be used to indicate a mutation in the gene (see below for P53). Since it is a sensitive in-situ technique, the number of advantages are high, particularly the comparison of the difference in expression within the histological lesions and the normal surrounding tissue, the change in subcellular compartment expression (nucleus, cytoplasm, membrane) and the use of internal control of protein expression (e.g. expression of a protein in blood vessels). The limits are the variable specificity of the antibodies, which needs cautious validation, and the ability of a protein to be detected on formalin fixed-samples and not only on frozen ones

\section{Oncogenes and tumour suppressor genes}

Different families of genes are implicated in the process of tumour growth and metastasis (fig. 4). The first family of genes involved, the growth factors and their receptors, are located at the cell membrane [36-39]. The epidermal growth factor receptor is overexpressed

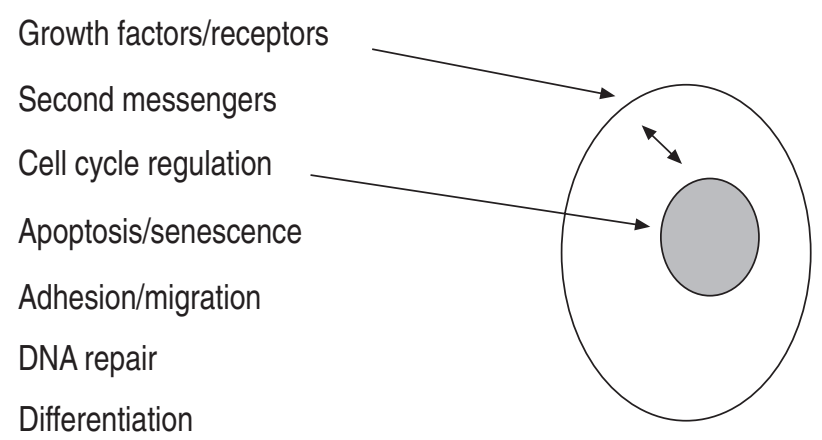

Fig. 4.-Different families of genes implicated in the process of tumour growth and metastasis. DNA: deoxyribonucleic acid. 
in at least $80 \%$ of nonsmall cell lung cancers (NSCLC). Blocking agents, such as antibodies or new molecular agents, have a potential role in the chemopreventative treatment of such overexpressed growth factor receptors.

Second messengers allow transmition of the proliferation signal from the cell membrane to the nucleus. Of these second messengers, ras seems particularly useful for the early detection of adenocarcinoma [4047]. Most ras mutations affect codon 12 of K-ras in $30 \%$ of adenocarcinomas in smokers and $5 \%$ in nonsmokers. Interestingly, the K-ras mutation seems specific for cancer and precancerous states, since it has been described in severe alveolar dysplasia and atypical alveolar hyperplasia [21, 22]. The identification of a mutation in this gene in sputum, for example, could correlate with the development of cancer in the lung. The study of mutations in this gene appears to be interesting, since there are few mutations to study and the techniques are very sensitive. One cell with a ras mutant allele can be detected in a background of 10,000 cells with wild-type alleles [48].

The cell cycle regulation genes gather different gene networks that are involved in the progression of a dividing cell through successive of phases of the cell cycle. Some of these genes control the proliferation process at the different checkpoints of the cycle (G1-S, G2-M) and are prone to deregulation during the oncogenic process. One of the most important networks is the P53-retinoblastoma gene (Rb) pathway (fig. 5). $\mathrm{Rb}$ proteins, D-cyclins and cyclin-dependant kinase inhibitors belong to a group of genes of the internal cell cycle machinery that might be deregulated. The external machinery comprises P53, MdM2 and Waf1 P21 proteins.

P53 has been called "guardian of the genome" [49, 50], as once it is activated, as a result of genotoxic stress, it reduces $\mathrm{Rb}$ phosphorylation and induces a stop at the G1-S check-point to allow DNA repair or to drive the cell to an apoptotic programme through bax/bcl 2 and other P53-induced gene regulation processes. Inactivation of P53 leads to a loss of control of the G1 arrest and also to a loss to apoptosis leading to uncontrolled growth.

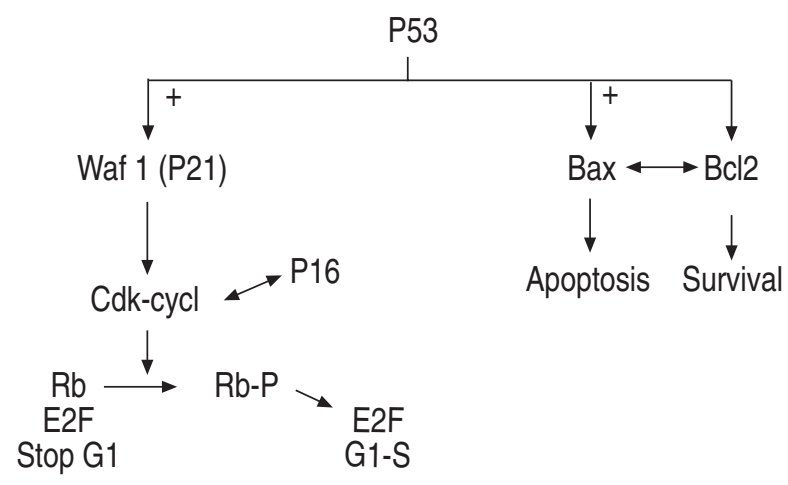

Fig. 5.- Signalling pathway of the P53 and retinoblastoma (Rb) gene, which controls the G1-S check point of the cell cycle and apoptosis. Bax, bcl2, Wafi (P21), P16 and other cyclin-dependent kinases $(\mathrm{cdk}-\mathrm{cycl})$ are a part of the interegulated genes.
Mutation of P53 is very frequent in lung cancer and occurs in $50 \%$ of NSCLCs and $75 \%$ of small cell lung cancers (SCLCs) [51]. Most of the mutated proteins have an increase half life, with an accumulation of P53 protein in the nucleus that can be shown easily by immunohistochemistry. If accumulation of P53 protein in $>20 \%$ of the cells is quite synonymous of a mutation [34], 20\% of the mutations may affect nonsense codon or splicing sites with truncated messenger RNA. In these cases, sequencing techniques are necessary to identify the mutation $[52,53]$. Nevertheless, immunohistochemical accumulation of P53 on a bronchial biopsy seems a very interesting biomarker. It is absent in metaplasia, and when present in dysplasia it seems well correlated with the presence or the outcome of a cancer [54] (fig. 6). At the present time, mutations of P53 may be studied on microarrays since the large number of mutations to be studied is one of the limits of ancillary techniques [55-63].

The $\mathrm{Rb}$ gene [64] is inactivated in $>80 \%$ of highgrade neuroendocrine lung tumours, particularly SCLC [65-67], but it seems difficult to propose the study of this gene as a biomarker at the present time since preneoplastic lesions of these tumours are not known and $\mathrm{Rb}$ loss is present in only $10 \%$ of the preneoplastic lesions of squamous cancer. In contrast, P16 and cyclin-D1, which regulate $\mathrm{Rb}$ phosphorylation, are deregulated in $50 \%$ of NSCLC. The current authors have observed a loss of P16 protein expression at an increased rate in different preneoplastic lesions using immunochemistry on bronchial biopsies. This loss of expression was associated, or not, with a progressive overexpression of cyclin-D1 [68, 69]. The potential mechanisms for P16 inactivation, leading to P16 loss of protein expression, are homozygous deletion, methylation and mutation in decreasing order of frequency [25]. P16 seems to be an interesting biomarker when using immunochemistry on bronchial or lung biopsies, on cell preparations such as bronchial aspiration or sputum, or in circulating DNA from the blood. Gene silencing may be proved by the presence of aberrant methylation. Abnormalities on P19, alternative reading frame product of the INK $4 \mathrm{a}$, a common locus

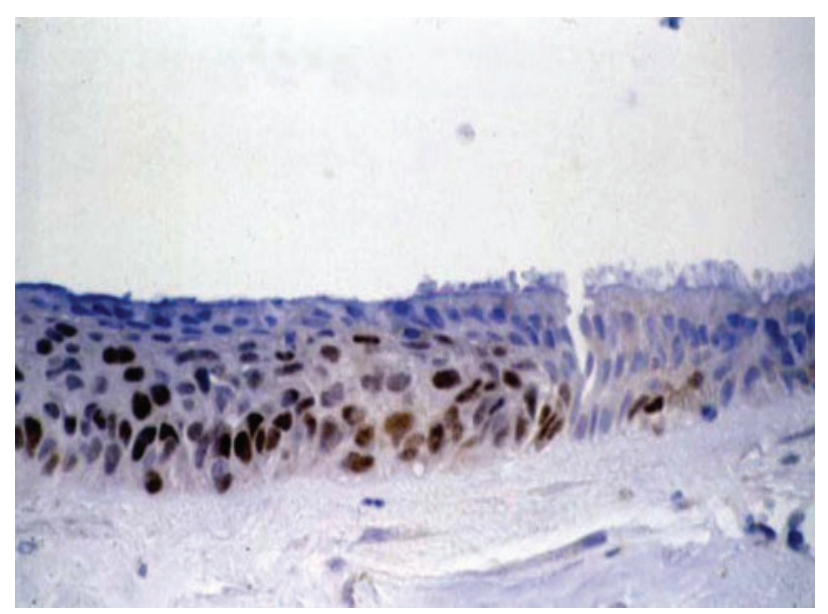

Fig. 6. - Nuclear acculmulation of mutated P53 in bronchial dysplasia. 
with P16 seems important in lung carcinogenesis [70, 71] but its role as a biomarker has to be evaluated.

The deregulation of apoptosis may be studied by the expression of two genes: bax and bcl2 [72-74]. Bax is an apoptotic gene whose dimeric protein product formation induces apoptosis. On the contrary, bcl2 is a survival (antiapoptotic) gene and the dimer bax/bcl2 induces a neutralisation of bax and a loss of apoptosis. $\mathrm{Bax} / \mathrm{bcl} 2$ deregulation, as the inversion of the bax/bcl2 ratio, has been studied in preneoplastic lesions [54]. A ratio $<1$, indicating hyperexpression of bcl 2 and loss of bax as compared to normal bronchial epithelium, has been shown to increase with the severity of the preneoplastic lesions, from low grade to high grade. FHIT is also implicated in the apoptotic process; this gene is situated on $3 p$, which is frequently lost in lung cancer. Inactivation of this gene through LOH or loss of protein expression using immunochemistry has been shown as an early event in bronchial biopsies and was also found in sputum from smokers [75].

The senescence process is also deregulated in preneoplastic and neoplastic lesions. Telomeres are located at the end of all eukaryotic chromosomes [76, 77, 78] and are important in maintaining their stability. Foetal cells and some stem cells have telomerase activity to compensate for telomere shortening during replication (fig. 7), whereas the vast majority of normal adult cells do not exhibit telomerase activity. However, telomerase activity is detectable in most human cancers, particularly in SCLC and NSCLC. Telomerase activity may be also detected in precancerous lesions of the lung, reflecting the early involvement of the molecule in lung tumour genesis [79].

The four gene families mentioned above (growth factor/receptor, second messenger, cell cycle regulation, apoptosis/senescence families) are not the only ones involved in the process of tumour growth and metastasis, since adhesion/migration genes, DNA repair genes, differentiation genes and probably many others can be implicated in this complex process. At the present time, silencing or activation of different genes in these families have been proposed as biomarkers and the silencing of these genes through aberrant methylation is presently being studied on different samples, particularly in sputum and circulating DNA.

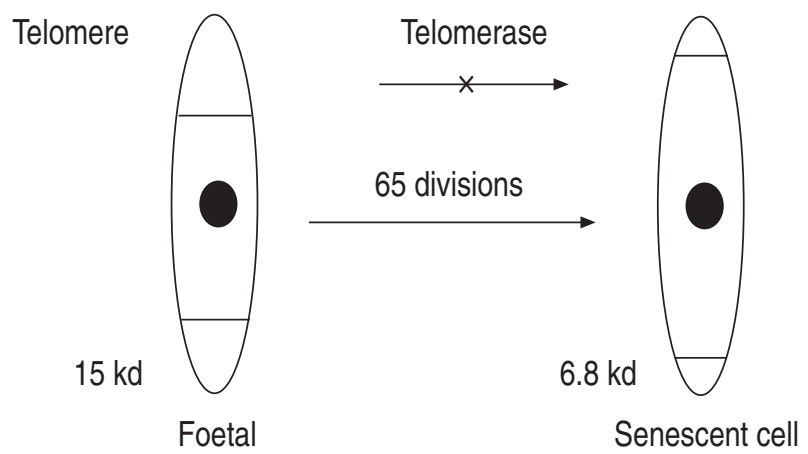

Fig. 7.-Telemorase, when activated, avoids shortening of the telomere, which leads to senescence.

\section{What makes a good biomarker?}

A good biomarker should require none or a minimally invasive technique of sampling [80]. Bronchial or lung biopsies are important to set up the value of one biomarker, but are difficult to propose for a screening programme. Bronchoalveolar lavage or brushings are less invasive but still require an endoscopy [81-83]. Sputum seems very interesting [84], but besides the problem of conservation or preparation, the main problem is the time necessary to collect good quality induced sputum (15-30 min with a specialised nurse or technician). However, a 3-day collection on Saccomano fixative seems to be good enough to study DNA but not RNA modifications (unpublished data). Circulating DNA in blood seems a very promising way to study biomarkers for early detection of lung cancer. Quantitative PCR only requires a very small amount of tumour DNA. Although the origin remains obscure, the presence of circulating tumour DNA is well established and could appear at the first stage of the disease before a metastasis process $[85,86]$.

A good biomarker must show a significant difference between the tumour and normal tissue and should correlate with cancer progression. To be applied in a screening programme, it should be able to be performed at a low cost and a high efficiency. Ideally, it should be used to target the treatment or to control its efficacy (intermediate end-point marker) once a chemoprevention programme has been proposed.

\section{Clinical application}

Spiral computed tomography (CT) is undoubtedly the best technique to detect small peripheral nodules early on. However, even if it is more accurate than chest radiography [87], spiral CT may not detect early proximal bronchial lesions. In the study of HenschKe et al. [87], only one proximal bronchial cancer was detected in a group of 27 cancers. Probably, the amelioration of the techniques will allow for better detection of these lesions. Sputum cytology is a highly specific technique, but unfortunately the sensitivity is very low. In the study of J. Jett (J. Jett, Mayo Clinic, Boston, MA, USA, personal communication), for example, only two cancers were detected on sputum cytology in 1,500 patients. As well as its lack of sensitivity, sputum cytology is also a time consuming technique. Automated cytology has been validated for cervical preparations, but even if different techniques are actually proposed, none have been validated on sputum [88].

The best way to view and biopsy proximal lesions from the trachea to most of the subsegmental bronchi is via fibreoptic bronchoscopy. This technique can also not be proposed as a screening technique since it is an invasive procedure that may not be cost effective unless it is applied to a highly selected population of patients. Fluorescent fibreoptic bronchoscopy clearly increases the sensitivity of detection of very early lesions. The first system developed by LAM et al. [14] was the Life System. Illumination with a determined wavelength $(520 \mu \mathrm{m})$ laser light induces an auto 
fluorescence of the bronchial epithelium, probably due to the reflection of the light on the inner part of the bronchial wall (collagen). When there is an increase of the thickness of the bronchial mucosa it appears as a dark brown area, corresponding to preneoplastic, micro-invasive or to inflammatory lesions of the bronchial wall. As this allows for a targeting of the biopsy it clearly increases the rate of detection of preneoplastic lesions. The relative sensitivity was multiplied by 4.7 for low-grade preneoplastic lesions and by 2.3 for high-grade lesions, as compared to white light bronchoscopy in a study of 278 patients recently published by the current authors [89]. However, the specificity of this technique is not very high (55\% in the current authors' study). This study allows a better determination of the at risk population. The duration and intensity of tobacco consumption is correlated with a high rate of preneoplastic lesions but the most important factor is a history of squamous cancer. In the present authors' series, the 11 patients with lung cancer cured by surgical resection had a history of squamous cancer, no preneoplastic lesions were detected in the bronchi of patients with an history of adenocarcinoma. Fifty-five per cent of the patients had several high-grade lesions and in $40 \%$ of the cases, these lesions were bilateral. This clearly illustrates the theory of field cancerisation. There is no consensus at the present time on the way to manage these lesions. CIS seems to progress to invasive cancer in most cases, particularly after intraluminal treatment with electrocautery or photodynamic therapy $[16,17,90]$. Moderate and severe dysplasia are considered as preneoplastic lesions due to the risk of progression of these lesions or the accumulation of molecular abnormalities at their level and most of the groups consider that they require a local treatment with electrocautery. The discussion persists on metaplasia and mild dysplasia and a randomised trial is underway. However, it is very difficult to prove the natural history of these lesions and the role of treatment intervention. The new World Health Organization/International Association for the Study of Lung Cancer (IASLC) classification [13] gives the pathologist better elements to classify these lesions and the interobserver variability will probably decrease with training of the pathologists, as they were not really aware of these lesions up to now $[91,92]$. The training and the interobserver variability will also ameliorate between the endoscopists using different types of fluorescent endoscopic devices [93]. The two main problems are the representativity and the reproducibility of the biopsies. When the number of biopsies increases from one to five on a bronchial division, the rate of finding more severe lesions, e.g. microinvasive carcinoma instead of CIS, increases as well. The repetition of biopsy on the same spot several months later is very difficult to interpret. The site of a preceding biopsy is easy to locate, owing to the fact that there is a dark spot under autofluorescence examination in the area of a previous biopsy. But when the new biopsy shows a worsening of the lesion, it is difficult to prove if it is really a worsening or a lack of sampling on the first biopsy. When the new biopsies fail to show preneoplastic lesions, either the first biopsy removed all of them or it corresponds to amelioration or a real cure of the lesions. These two problems, in particular, obscure the natural history of these lesions and one must be cautious when interpreting the evolution of those during longitudinal follow-up of a given lesion.

Spiral CT and fluorescent bronchoscopy clearly increase the rate of detection of preneoplastic or early cancer. The role of the biomarkers, however, may be important either to select a population that would require radiological or endoscopic screening programmes or to recommend more aggressive diagnostic procedures or therapeutic interventions when radiological or endoscopic lesions have been found. The present authors recently showed that the number of molecular abnormalities on bronchial preneoplastic lesions correlates with an event of cancer [55]. To evaluate the role of these biomarkers two different protocols were initiated as follows: Biomarkscan, a pilot nonrandomised early detection programme in very high-risk patients; and Depiscan, part of the French screening randomised control to trial in asymptomatic smokers.

In the Biomarkscan programme the patient will have spiral CT and induced sputum and blood sampling every year, for 5 yrs. A fluorescent bronchoscopy will be performed every 2 yrs for the patients with an history of squamous cancer and at the beginning for the group of symptomatic smokers, and repeated after 3 or 6 months when a high-grade or low-grade lesion is found. All the patients and the volunteers recruited in the control group will have a questionnaire about respiratory symptoms and tobacco consumption and tobacco cessation will be recommended. The patients in the first group will include those with an history of lung or upper airways cancer cured by surgery; in the second group, symptomatic smokers; in the third group, patients with a cancer at the time of inclusion in the protocol (this will be used as a positive control group for the determination and the follow-up of biomarkers in blood and sputum); and the last group, normal nonsmoking volunteers who will be used as a negative control group for the biomarkers. The aims of these protocols are to increase early detection using spiral CT and biomarkers, to identify biomarkers predictive of irreversibility and progression in high-grade preneoplastic lesions, to draw a molecular and genetic identity card to assess the risk of cancer and, finally, to establish a phenotypic receptor characterisation in order to set up a chemoprevention programme. A very preliminary result of this programme was the detection of 23 aberrant methylations in the promoters of six TSG genes (P16, FHIT, DAP-kinase, $\mathrm{O}^{6}$-MGMT, TIMP-3, E-cadherin) in the bronchial aspiration of the first 76 patients. Four patients had two methylations of these genes and five patients had methylation of at least one gene without cancer at the time of endoscopy.

The Depiscan programme is a national randomised programme to assess the value of spiral CT in the reduction of specific mortality of lung cancer. The patients are not the same since they are asymptomatic smokers. In those patients, blood and sputum sampling 
will be performed as well as repeated spiral CT to asses the modification of the biomarkers. Those two protocols are included in the international collaboration driven by the European Lung Cancer Early Detection (EULCED) Group [81, 82].

\section{Conclusion}

Clearly, the future of the use of biomarkers will have to go through miniaturised and automatic techniques, probably using microarrays. Unfortunately, in lung cancer there are no sensitive and specific biomarkers, such as prostate specific antigen in prostate cancer. Several biomarkers will probably have to be used together, including P53, ras and the methylation of different genes. This will increase the cost of using biomarkers; however the huge amount of money generated by tobacco use could be better directed towards benefiting smokers in this way. Conversely, even if early detection techniques seem promising, it would be unethical for physicians to not concentrate on the only way to reduce the incidence of lung cancer, which is smoking cessation programmes and smoking prevention programmes.

Acknowledgements. The authors would like to thank M. Lorinet and I. Berruyer for typing the manuscript.

\section{References}

1. Schottenfeld D. Etiology and epidemiology of lung cancer. In: Pass HI, Mitchell JB, Johnson DH, Turrisi AT, Minna JD, eds. Lung Cancer: Principles and practice. Philadelphia, USA, Lippincott Williams and Wilkins, 2000; pp. 367-388.

2. Boyle P, Gandini S, Gray N. Epidemiology of lung cancer: a century of great success and ignominious failure. In: Hansen HH, ed. Textbook of lung cancer. London, UK, Martin Dunitz, 2000; pp. 13-25.

3. Black RJ, Bray F, Ferlay J, Parkin DM. Cancer incidence and mortality in the European Union: Cancer registry data and estimates of national incidence for 1990. Eur J Cancer 1997; 33: 1075-1107.

4. Minna JD, Sekido Y, Fong K, Gazdar AF. Molecular biology of lung cancer. In: Devita VT, Hellman S, Rosenberg SA, eds. Cancer: Principles and practice of oncology, 5th edition. Philadelphia, Lippincott, 1997; 30.I, 849-857.

5. Sherr CJ. Cancer cell cycles. Science 1996; 274: 1672 1677.

6. Hunter T. Oncoprotein networks. Cell 1997; 88: 333 346.

7. Michalides RJA. Deregulation of the cell cycle in lung cancer. In: Brambilla E, Brambilla C, eds. Fundamental biology and clinical management. M. Dekker New-York, Basel, 1998; pp. 211-225.

8. Kishimoto Y, Sugio K, Hung JY, et al. Allele specific loss in chomosome $9 \mathrm{p}$ loci in preneoplastic lesions accompanying non small cell lung cancers. $J$ Natl Cancer Inst 1995; 87: 1224-1229.

9. Chung GTY, Sundaresan V, Hasleton P, Rudd R,
Taylor R, Rabbits P. Sequential molecular genetic changes in lung cancer development. Oncogene 1995; 11: 2591-2598.

10. Mao L, Lee JS, Kurie JM, et al. Clonal genetic alterations in the lung of current and former smokers. J Nat Cancer Inst 1997; 89: 857-862.

11. Wistuba II, Lam S, Behrens C, et al. Molecular damage in the bronchial epithelium of current and former smokers. J Nat Cancer Inst 1997; 89: 13661373.

12. Auerbach $\mathrm{O}$, Gere B, Forman JB, et al. Changes in bronchial epithelium in relation to smoking and cancer of the lung. $N$ Engl J Med 1957; 256: 97-104.

13. Travis WD, Colby TB, Corrin B, Shimosato Y, Brambilla E. Histological typing of tumours of lung and pleura. In: Sobin LH, ed. World Health Organization International Classification of Tumours, 3rd edition. New York, Springer-Verlag, 1999; p. 245.

14. Lam S, Kennedy T, Unger M, et al. Localization of bronchial intraepithelial neoplastic lesions by fluorescence bronchoscope. Chest 1998; 113: 696-702.

15. Band P, Feldstein M, Saccomanno G. Reversibility of bronchial marked atypia: implication for chemoprevention. Cancer Detect Treatment 1986; 9: 157-160.

16. Venman BJW, van Boxem TJM, Smit EF, Postmus PE, Sutedja TG. Outcome of bronchial carcinoma in situ. Chest 2000; 117: 1572-1576.

17. Bota S, Auliac JB, Paris C, et al. Follow-up of bronchial precancerous lesions and carcinoma in situ using fluorescence endoscopy. Am J Respir Crit Care Med 2001; 164: 1688-1693.

18. Wistuba II, Lam S, Behrens C, et al. Molecular damage in the bronchial epithelium of current and former smokers. J Nat Cancer Inst 1997; 89: 13661373.

19. Mao L, Lee JS, Kurie JM, et al. Clonal genetic alterations in the lung of current and former smokers. J Nat Cancer Inst 1997; 89: 857-862.

20. Wistuba II, Behrens C, Milchgrub S, et al. Sequential molecular abnormalities are involved in the multistage development of squamous cell lung carcinoma. Oncogene 1999; 18: 643-650.

21. Westra WH, Baas IO, Hruban RH. Atypical alveolar hyperplasias (AAHs) of the lung frequently harbor K-ras mutations: evidence to implicate AAH as the precursor lesion of lung adenocarcinoma. Mod Pathol 1996; 23: 164-167.

22. Kerr KM, Cary FA, King G, Lamb D. Atypical adenomatous hyperplasia: Relationship with pulmonary adenocarcinoma, p53, and c-erB-2 expression. J Pathol 1994; 174: 249-256.

23. Sozzi G. Deletions of the short arm of chromosome 3 and the FHIT gene in lung cancer. In: Brambilla E, Brambilla C, eds. Fundamental biology and clinical management. M. Dekker New-York, Basel, 1998; pp. 157-171.

24. Zhou W, Goodman SN, Galizia G, et al. Counting alleles to predict recurrence of early stage resected colo-rectal cancers. Lancet 2002; 359: 219-225.

25. Gazzeri S, Gouyer V, Vour'ch C, Brambilla C, Brambilla E. Mechanism of $\mathrm{p} 16^{\mathrm{INK} 4 \mathrm{~A}}$ inactivation in non small-cell lung cancers. Oncogene 1998; 16: 497505.

26. Belinsky SA, Nikula KJ, Palmisano WA, et al. Aberrant methylation of p16INK4a is an early event in lung cancer and a potential biomarker for early 
diagnosis. Proc Natl Acad Sci USA 1998; 95: 1189111896.

27. Zochbauer-Muller S, Fong KM, Virmani AK, Geradts J, Gazdar AF, Minna JD. Aberrant promoter methylation of multiple genes in non-small cell lung cancers. Cancer Res 2001; 61: 249-255.

28. Palmisano WA, Divine KK, Saccomanno G, et al. Predicting lung cancer by detecting aberrant promoter methylation in sputum. Cancer Res 2000; 60: 5954 5958.

29. Esteller M, Sanchez-Cespedes M, Rosell R, Sidransky D, Baylin SB, Herman JG. Detection of aberrant promoter hypermethylation of tumor suppressor genes in serum DNA from non-small cell lung cancer patients. Cancer Res 1999; 59: 67-70.

30. Kurakawa E, Shimamoto T, Utsumi K, Hirano T, Kato $\mathrm{H}$, Ohyashiki K. Hypermethylation of p16(INK4a) and p15(INK4b) genes in non-small cell lung cancer. Int J Oncol 2001; 19: 277-281.

31. Chaussade L, Eymin B, Brambilla E, Gazzeri S. Expression of p15 and p15.5 products in neuroendocrine lung tumours: relationship with $\mathrm{p} 15^{\mathrm{INK} 4 \mathrm{~b}}$ methylation status. Oncogene 2001; 20: 6587-6596.

32. Virmani AK, Rathi A, Zochbauer-Muller S, et al. Promoter methylation and silencing of the retinoic acid receptor-beta gene in lung carcinomas. $J$ Natl Cancer Inst 2000; 92: 1303-1307.

33. Hainaut P, Hollstein M. p53 and human cancer: the first ten thousand mutations. Adv Cancer Res 2000; 77: 82-37.

34. Brambilla E, Gazzeri S, Moro Sibilot D, et al. Immunohistochemical study of p53 in human lung carcinomas. Am J Pathol 1993; 143: 199-210.

35. Brambilla E, Gazzeri S. P53 pathway and lung cancer. In: Brambilla E, Brambilla $\mathrm{C}$, eds. Fundamental biology and clinical management. M Dekker NewYork, Basel, 1998; pp. 173-190.

36. Rusch V, Klimstra D, Venkatraman E, Pisters PWT, Langenfeld J, Dmitrovsky E. Overexpression of the epidermal growth factor receptor and its ligand transforming growth factor $\alpha$ is frequent in resectable non-small cell lung cancer but does not predict tumor progression. Clin Cancer Res 1997; 3: 515-522.

37. Schneider PM, Hung MC, Chiocca SM, et al. Differential expression of the c-erbB-2 gene in human small cell an non-small cell lung cancer. Cancer Res 1989; 49: 4968-4971.

38. Liu C, Tsao MS. In vitro and in vivo expressions of transforming growth factor and tyrosine kinase receptors in human non-small-cell lung carcinomas. Am J Pathol 1993; 142: 1155-1162.

39. Kern J, Schwartz DA, Nordberg JE, et al. p185neu expression in human adenocarcinomas predicts shortened survival. Cancer Res 1990; 50: 5184-5191.

40. Jacobson DR. Ras mutations in lung cancer. In: Brambilla E, Brambilla C, eds. Fundamental biology and clinical management. M. Dekker New-York, Basel, 1998; pp. 139-156.

41. Rodenhuis S, Slebos RJC. Significance of ras oncogene activation in human lung cancer. Cancer Res 1992; 52: 2665-2669.

42. Slebos RJC, Kibbelaar RE, Dalesio MDO. K-ras oncogene activation as a prognostic marker in adenocarcinoma of the lung. N Eng J Med 1990; 323: $561-565$.

43. Suggio K, Ishida T, Yokoyama H, Inoue T, Sugimachi $\mathrm{K}$, Sasazuki T. Ras gene mutation as a prognostic marker in adenocarcinoma of the human lung without lymph node metastasis. Cancer Res 1992; 52: 2903-2906.

44. Rosell R, Li S, Skacel Z, et al. Prognostic impact of mutated K-ras gene in surgically resected non-small cell lung cancer patients. Oncogene 1993; 8: $2407-$ 2412.

45. Rosell R, Li S, Anton A, et al. Prognostic value of K-ras genotypes in patients with advanced non-small cell lung cancer receiving carboplatin with either intravenous or chronic oral dose etoposide. Int $J$ Oncol 1994; 5: 169-176.

46. Keohavong P, Demichele MAA, Malacrinos AC, Landreneau RJ, Weyant RJ, Siegfried RJW. Detection of K-ras mutations in lung carcinomas: relationship to prognosis. Clin Cancer Res 1996; 2: 411-418.

47. Urban T, Ricci S, Lacave R, et al. Codon 12 ki-ras mutation in non-small cell lung cancer: comparative evaluation in tumoral and non-tumoral lung. $\mathrm{Br} J$ Cancer 1996; 74: 1051-1055.

48. Mills NE, Fishman CL, Scholes J, et al. Detection of $\mathrm{K}$-ras oncogene mutations in bronchioalveolar lavage fluid for lung cancer diagnosis. J Natl Cancer Inst 1995; 87: 1056-1060.

49. Lane D. P53, guardian of the genome. Nature 1992; 358: 15-16.

50. Levine AJ. P53, the cellular gatekeeper for growth and division. Cell 1997; 88: 323-331.

51. Gazzeri S, Brambilla E, Caron de Fromentel C, et al. p53 genetic abnormalities and myc activation in human lung carcinomas. Int J Cancer 1994; 58: 24-32.

52. Greenblatt MS, Bennet WP, Hollstein M, Harris CC. Mutations in the P53 tumor suppressor gene: clues to cancer etiology and molecular pathogenesis. Cancer Res 1994; 54: 4855-4878.

53. Denissenko MF, Pao A, Tang MS, Pfeifer GP. Preferential formation of benzo(a)pyrene adducts at lung cancer mutational hotspots in P53. Science 1996; 274: 430-432.

54. Brambilla E, Gazzeri S, Lantuejoul S, et al. P53 mutant immunophenotype and deregulation of P53 transcription pathway $(\mathrm{Bcl} 2$, Bax, Waf1) in precursor bronchial lesions of lung cancer. Clin Cancer Res 1998; 4: 1609-1618.

55. Pastorino U, Andreola S, Tagliabue E, et al. Immunocytochemical markers in stage I lung cancer (NSCLC): relevance to prognosis. J Clin Oncol 1997; 15: 28582865.

56. Cai DW, Mukhopakhyay T, Liu Y, Fujiwara T, Roth JA. Stable expression of the wild-type p53 gene in human lung cancer cells after retrovirus-mediated gene transfer. Human Gene Therapy 1993; 4: 617-624.

57. Takahashi T, Carbone D, Takahashi T, et al. Wildtype but not mutant p53 suppresses the growth of human lung cancer cells bearing multiples genetic lesions. Cancer Res 1992; 52: 2340-2343.

58. Brambilla E, Brambilla C. P53 and lung cancer. Path Biol 1997; 45: 852-863.

59. Boers JE, Ten-Velde GPM, Thunnissen FBJM. P53 in squamous metaplasia: a marker for risk of respiratory tract carcinoma. Am J Respir Crit Care Med 1996; 153: 411-416.

60. Ponticiello A, Barra E, Giani E, Bocchino M, Sanduzzi A. P53 immunohistochemistry can identify bronchial dysplastic lesions proceeding to lung cancer: a prospective study. Eur Respir J 2000; 15: 547-552.

61. Wu X, Bayle JH, Olson D, Levine AJ. The P53-mdm2 
autoregulatory feedback loop. Genes Dev 1993; 7: $1126-1332$.

62. Xiao ZX, Chen J, Levine AJ, et al. Interaction between the retinoblastoma protein and the oncoprotein mdm2. Nature 1996; 372: 694-698.

63. Prives C, Hall PA. The P53 pathway. J Pathol 1999; 187: $112-126$

64. Weinberg RA. The retinoblastoma protein and cell cycle control. Cell 1995; 81: 323-330.

65. Gazzeri S, Gouyer V. Inactivation of RB gene and pRB function in lung cancer. In: Brambilla $\mathrm{E}$, Brambilla C, eds. Fundamental biology and clinical management. M. Dekker New-York, Basel, 1998; pp. 191-209.

66. Gouyer V, Gazzeri S, Brambilla E, et al. Loss of heterozygosity at the RB locus in primary malignant neuroendocrine lung carcinomas. Int J Cancer 1994; 58: 818-824.

67. Kratzke RA, Greatens TM, Rubins JB, et al. Rb and p16 ${ }^{\mathrm{INK} 4}$ expression in resected non small cell lung tumors. Cancer Res 1996; 56: 3415-3420.

68. Brambilla E, Moro Sibilot D, Gazzeri S, Brambilla C. Alterations of Rb, P16 ${ }^{\mathrm{INK} 4}$, Cyclin D1 expressions in non small cell lung carcinoma and their clinical significance. J Pathol 1999; 188: 351-360.

69. Brambilla E, Gazzeri S, Moro Sibilot D, Lantuejoul S, Veyrenc S, Brambilla C. Alterations of $\mathrm{Rb}$ pathway (Rb-P16 ${ }^{\mathrm{INK} 4}$-Cyclin D1) in preinvasive bronchial lesions. Clin Cancer Res 1999; 5: 243-250.

70. Kamijo T, Zindy F, Roussel MF, et al. Tumor suppression at the mouse INK4a locus mediated by the alternative reading frame product $\mathrm{p} 19^{\mathrm{ARF}}$. Cell 1997; 91: 649-659.

71. Gazzeri S, Della Valle V, Chaussade L, Brambilla C, Larsen CJ, Brambilla E. The human p $19^{\mathrm{ARF}}$ protein encoded by the $\beta$ transcript of the p $16^{\mathrm{INK} 4}$ gene is frequently lost in small cell lung tumors. Cancer Res 1998; 58: 3926-3931.

72. Brambilla E, Negoescu A, Gazzeri S, et al. Apoptosisrelated factors $\mathrm{P} 53, \mathrm{Bcl} 2$, and $\mathrm{Bax}$ in neuroendocrine lung tumors. Am J Pathol 1996; 149: 1941-1952.

73. Pezzela F, Turley $\mathrm{H}$, Kuzu I, et al. $\mathrm{Bcl}_{2}$ protein in nonsmall-cell lung carcinoma. N Engl J Medicine 1993; 329: 690-694

74. Fontanini G, Vignati S, Bigini $\mathrm{D}$, et al. $\mathrm{Bcl}_{2}$ protein: a prognostic factor inversely correlated to p53 in non-small-cell lung cancer. $B r J$ Cancer 1995; 71: 1003-1007.

75. Sozzi G, Pastorino U, Moiraghi L, et al. Loss of FHIT function in lung cancer and preinvasive bronchial lesions. Cancer Res 1998; 58: 5032-5037.

76. Harley CB. Telomere loss: mitotic clock or genetic time bomb? Mut Res 1991; 256: 271-282.

77. Rathi A, Kazuo Y, Onuki N, Virmani A, Gazdar AF. Telomerase and lung cancer. In: Brambilla E, Brambilla C, eds. Fundamental biology and clinical management. M. Dekker New-York, Basel, 1998; pp. 269-277.

78. Hiyama K, Hiyama E, Ishioka S, et al. Telomerase activity in small cell and non small cell lung cancers. J Natl Cancer Inst 1995; 87: 895-902.

79. Yashima K, Litzky LA, Kaiser L, et al. Telomerase expression in respiratory epithelium during the multistage pathogenesis of lung carcinomas. Cancer Res 1997; 57: 2373-2377.

80. Field JK, Brambilla C, Hirsch FR, et al. Molecular biomarkers workshop: a European strategy for developing lung cancer molecular diagnostics in high risk populations. Lung Cancer 2001; 31: 339-345.

81. Kersting M, Friedl C, Kraus A, Behn M, Pankow W, Schuermann M. Differential frequencies of $\mathrm{p} 16^{\mathrm{INKa}}$ promoter hypermethylation, p53 mutation, and K-ras mutation in exfoliative material mark the development of lung cancer in symptomatic chronic smokers. J Clin Oncol 2000; 18: 3221-3229.

82. Field JK, Liloglou T, Xinarianos $\mathrm{G}$, et al. Genetic alterations in bronchial lavage as a potential marker for individuals with a high risk of developing lung cancer. Cancer Res 1999; 59: 2690-2695.

83. Powell CA, Klares S, O'Connor G, Brody JS. Loss of heterozygosity in epithelial cells obtained by bronchial brushing: clinical utility in lung cancer. Clin Cancer Res 1999; 5: 2025-2034.

84. Mao L, Hruban RH, Boyle JO, Tockman M, Sidransky D. Detection of oncogene mutations in sputum precedes diagnosis of lung cancer. Cancer Res 1994; 54: 1634-1637.

85. Leon SA, Shapiro B, Sklaroff DM, Yaros MJ. Free DNA in the serum of cancer patients and the effect of therapy. Cancer Res 1977; 37: 646-650.

86. Stroun M, Anker P, Maurice P, Lyautey J, Lederrey C, Beljanski M. Neoplastic characteristics of the DNA found in the plasma of cancer patients. Oncology 1989; 46: 318-322.

87. Henschke C, McCauley D, Yankelevitz D, et al. Early lung cancer action project: overall design and findings from baseline screening. Lancet 1999; 354: 99-105.

88. Palcic B, Lam S, Hung J, MacAulay C. Detection and localization of early lung cancer by imaging techniques. Chest 1991; 99: 742-743.

89. Moro Sibilot D, Jeanmart M, Lantuejoul S, et al. Cigarette smoking, preinvasive bronchial lesions and autofluorescence bronchoscopy. Chest 2002; 122: 1902-1908.

90. Deygas N, Froudarakis M, Ozenne G, Vergnon JM. Cryotherapy in early superficial bronchogenic carcinoma. Chest 2001; 120: 26-31.

91. Hirsch FR, Gazdar AF, Gabrielson E, Lam S, Franklin WA. A histopathologic evaluation of premalignant and early malignant bronchial lesions: an interactive program based on internet digital images to improve WHO criteria for early diagnosis of lung cancer and for monitoring chemoprevention studies a SPORE collaborative project. Lung Cancer 2000; 29: 211.

92. Nicholson AG, Perry LJ, Cury PM, et al. Reproducibility of the WHO/IASLC grading system for preinvasive squamous lesions of the bronchus: a study of interobserver and intra-observer variation. Histopathology 2001; 38: 202-208.

93. Hirsch FR, Prindiville SA, Miller YE, et al. Fluorescence versus white-light bronchoscopy for detection of preneoplastic lesions: a randomized study. J Natl Cancer Inst 2001; 93: 1385-1391. 